\title{
Analysis of biomechanical behavior of 3D printed mandibular graft with porous scaffold structure designed by topological optimization
}

\author{
Jiajie $\mathrm{Hu}^{1}$, Joanne H. Wang ${ }^{2}$, Russel Wang ${ }^{3^{*}}$ (D) Xiong Bill Yư ${ }^{4}$, Yunfeng Liu ${ }^{5}$ and Dale A. Baur ${ }^{6}$
}

\begin{abstract}
Background: Our long-term goal is to design and manufacture a customized graft with porous scaffold structure for repairing large mandibular defects using topological optimization and 3D printing technology. The purpose of this study is to characterize the mechanical behavior of 3D printed anisotropic scaffolds as bone analogs by fused deposition modeling (FDM).

Methods: Cone beam computed tomography $(C B C T)$ images were used to reconstruct a 3D mandible and finite element models. A virtual sectioned-block of the mandible was used as the control group and the trabecular portion of the block was modified by topological optimization methods as experimental groups. FDM (FDM) printed samples at 0, 45 and 90 degrees with Poly-lactic acid (PLA) material under a three-point bending test. Finite element analysis was also used to validate the data obtained from the physical model tests.

Results: The ultimate load, yield load, failure deflection, yield deflection, stress, strain distribution, and porosity of scaffold structures were compared. The results show that the topological optimized graft had the best mechanical properties.

Conclusions: The results from mechanical tests on physical models and numerical simulations from this study show a great potential for topological optimization and 3D printing technology to be served in design and rapidly manufacturing of artificial porous grafts.

Keywords: 3D printing, Anisotropic behavior, Finite element analysis, Fused deposition modeling, Mandibular graft, Poly-lactic acid, Topological optimization
\end{abstract}

\section{Introduction}

Autograft and allograft are commonly used for bone grafting procedures to repair segmental bony defects, which usually result from trauma, infection and tumor resection of tumors [1-3]. The limitations of autografts are donor site morbidity [4], lack of bone volume for a large defect $[5,6]$, and possible nerve damage. While allografts are limited by anatomical variations, genetic differences, and possible disease transmission $[7,8]$. It is important to restore a critical-sized mandibular defect to

\footnotetext{
* Correspondence: rxw26@case.edu

${ }^{3}$ Department of Comprehensive Care, Case Western Reserve University

School of Dental Medicine, Cleveland, OH, USA

Full list of author information is available at the end of the article
}

its original size and shape to achieve desirable facial esthetics and functional outcome for subsequent prosthetic reconstruction. Microvascular free fibular graft is a common method for mandibular reconstructions to repair a large segmental defect [9-12]. It is impossible of using a fibular bone to match the shape and size of the resected portion of a mandible. Therefore, there are many prosthetic complications for those patients who received surgical and prosthetic reconstruction of the mandible [13]. One promising approach for obviating the aforementioned complication is the implementation of $3 \mathrm{D}$ printing strategies for the manufacturing of customized artificial bio-graft [14, 15].

(c) The Author(s). 2019 Open Access This article is distributed under the terms of the Creative Commons Attribution 4.0 International License (http://creativecommons.org/licenses/by/4.0/), which permits unrestricted use, distribution, and reproduction in any medium, provided you give appropriate credit to the original author(s) and the source, provide a link to the Creative Commons license, and indicate if changes were made. 
3D printing is a new digital modeling technology that emerged in the late 1980s. The core processing principle is that based on the principle of layer-by-layer overlay printing. The printing material could accurately be stacked to any shape of $3 \mathrm{D}$ complex objects in the control of computer programs $[16,17]$. In recent years, more and more attention has been paid to research and development of 3D printing technology in medicine. 3D printing is used to create objects with complex shapes and form. 3D "bioprinting" $[18,19]$ has a great potential for the application of using biomaterials to print bony defects for mandibular reconstructions resulting from tumor resection and trauma. In some cases, researchers can use 3D printing technology to produce personalized biomaterials that meet clinic needs. Schieker et al. [20] used 3D printing to create models with intricate internal structures with great precision in the range of micrometer level. The aperture size was as low as $450 \mu \mathrm{m}$ and the wall thickness was $330 \mu \mathrm{m}$. The mechanical strength of the structure was more than $22 \mathrm{MPa}$, which can meet the general requirements of an organ model. Yang et al. [21] used nano-hydroxyapatite and polyester microspheres to form polyester and nano-hydroxyapatite composites by 3D printing for medical applications. Habibovic et al. [22] demonstrated that complex shapes of implants could be $3 \mathrm{D}$ printed using calcium hydroxide phosphate and montmorillonite composites at body temperature with good mechanical properties for clinical use. The implanted fillers made from the two materials have varying degrees of osteoconduction and osteoinduction. However, studies found that there are significant changes of the mechanical properties resulting from anisotropy in 3D printing. Fused deposition modeling (FDM) has been widely used in all fields. Poly-Lactic Acid (PLA) is a commonly used material for 3D printing. [23] Because of the layer-by-layer manufacturing procedure, the model processed by FDM has a layered orthotropic microstructure, in which each layer consists of a contour and infill strips [24-26]. The infill structures may have different patterns depending on the printers.

Our long-term goal is to develop a new method to overcome the drawbacks of traditional bone grafting procedures for treating segmental bony defects by using 3D printing technology. 3D virtual mandibular grafts were designed based on cone beam computed tomography $(\mathrm{CBCT})$ images and subsequently fabricated by 3D FDM printing for reconstruction of a patient-specific mandibular defect. PLA is a promising thermoplastic aliphatic polyester and has been extensive studies for biomedical applications. It has been proven to be safe in clinical use such as temporary and long-term implantable devices, tissue engineering, and drug delivery systems [27-33]. PLA is a biocompatible material and its biodegradation in vivo is through hydrolysis to convert to water and carbon dioxide. The biodegradation behavior is a critical characteristic of the materials and the most important reason for the high interest in its use in medical applications and industry. It begins to decompose into lactic acid (LA), carbon dioxide and water once in contact with biological media. These products are metabolized in cells or excreted in urine and respiration. The 3D printing of customized grafts consist of the original shape and form of the cortical layer of a segmented mandibular with internal porous scaffold. The internal scaffolds had different strut designs to give strength during masticatory function. Topological optimization process was performed to provide an efficient way for the reduction of structure volume and the improvement of strength and stability [30-33]. Biomechanical behaviors of three types of grafts were compared and analyzed. The maximum load, yield load, failure deflection and yield deflection were measured from a three-point bending test for each type of the printed grafts. Maximum von Mises stress, principal strain, and displacement were calculated from finite element analysis using numerical simulation models.

\section{Materials \& methods CBCT image, 3D reconstruction and meshing}

$\mathrm{CBCT}$ has been widely used in treatment planning and diagnosis in implant dentistry [34-37]. Digital image data were obtained through a cone beam CT scanner $(120 \mathrm{~K} 70 \mathrm{~mA})$ with field of view of $23 \times 16 \mathrm{~cm}$ and voxel size of $0.39 \mathrm{~mm}$ from a 50 -year-old edentulous patient without any pathological condition in the mandible. A total of 512 images were saved as DICOM data files. Figure 1 shows the flowchart of this study.

A platform MIMICS (V16.0, Materialise, Belgium) was used to construct the 3D mandible based on the DICOM data files. The reconstruction procedure was as follows: first, a threshold for bony tissue segmentation was determined from the Hounsfield unit (HU) value and boundary. The mandible was separated as a sole mask through ROI (region of interest) extraction. Based on the mask, a $3 \mathrm{D}$ model represented as triangular mesh (also known as STL file) was created. Figure 2 shows the 3D model of the reconstructed mandible.

The triangular mesh is only a surface model. FEM calculation requires a volume mesh (tetrahedron) model. The MIMICS provides a mesh tool named 3-Matic (V8.0) for mesh generation and optimization. 3D virtual models can be smoothed and re-meshed to form volume meshes with high quality for numerical simulation. Geomagic (V12, 3D system, Rock Hill, SC, USA) software was used to complete the final editing of the volume mesh model. A portion of the reconstructed model was extracted for graft designs. The finalized volume mesh model in Geomagic program was directly imported to Abaqus (V6.13, Dassault System, Cedex, France) software for subsequent simulation and calculation. 


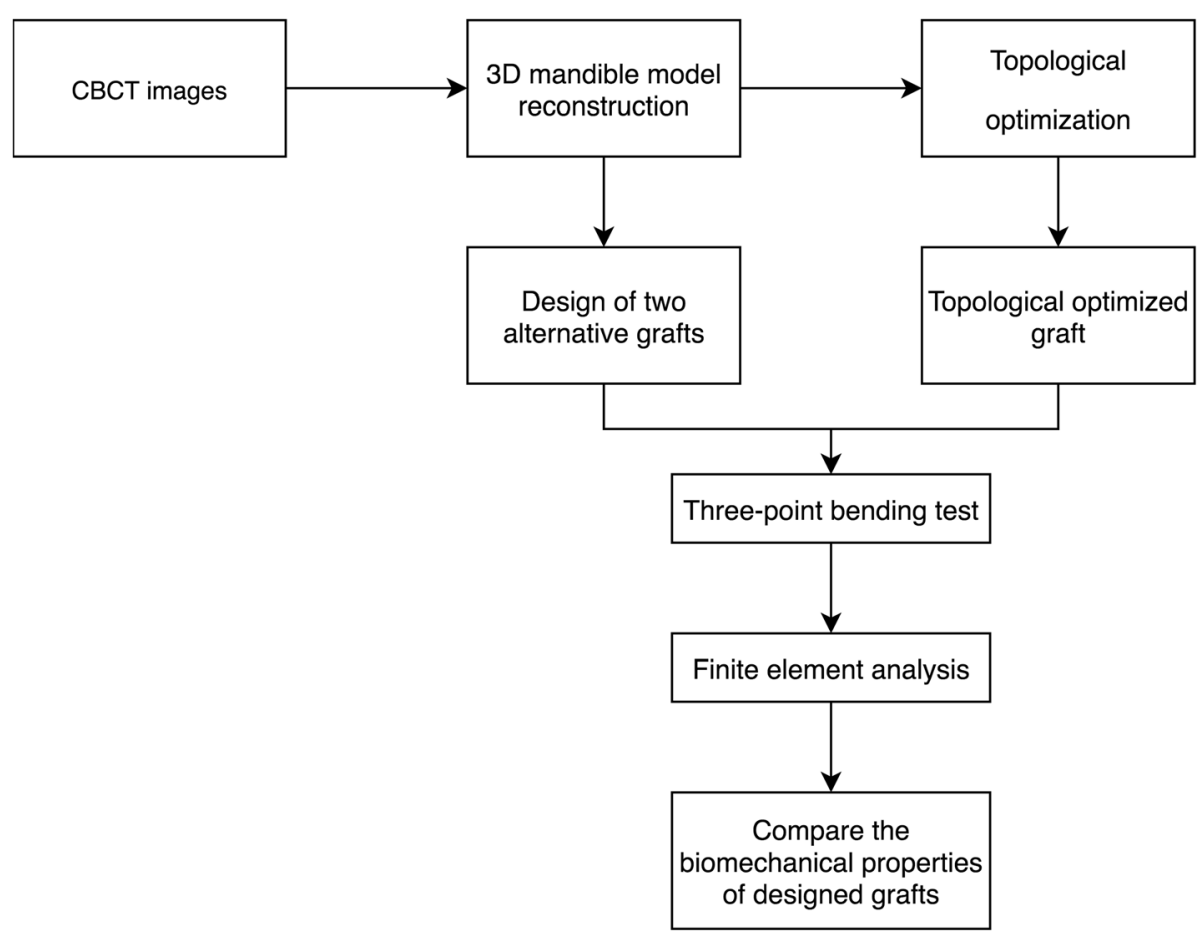

Fig. 1 Flowchart of the study

\section{Material properties of mandible}

Because of various degree of calcification of the mandible, different parts of the mandible have different elastic moduli and Poisson's ratio. Therefore, a mandibular model should be treated as an inhomogeneous material. Calculations of elastic modulus of bone in relation to bone mass density and Hounsfield unit are expressed in the following equations [38]:

$$
\begin{aligned}
& \rho=114+0.756 \times H U \\
& E=0.51 \times \rho^{1.37}
\end{aligned}
$$
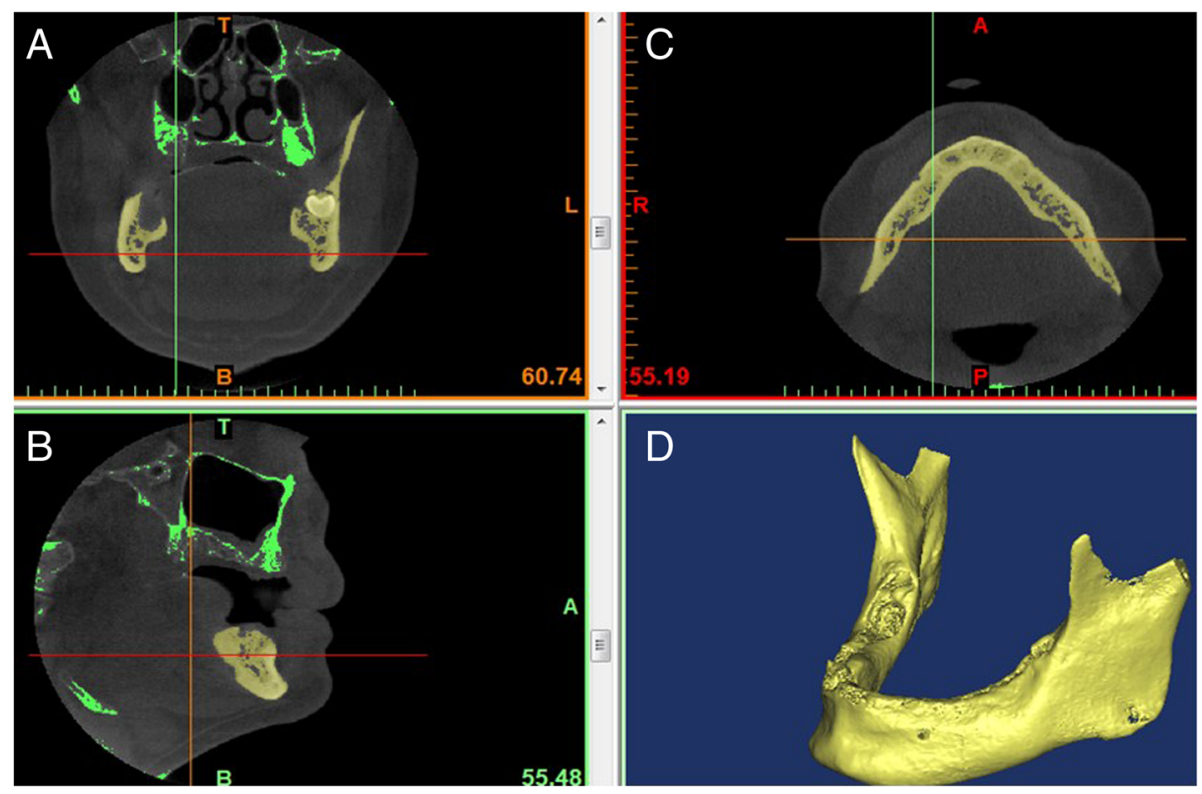

Fig. 2 3D virtual model of the mandible reconstructed from CT images. (a) Coronal plane, (b) transverse plane, (c) sagittal plane, and (d) 3D view 
where, $\rho$ is the density, $H U$ is the Hounsfield unit.; $E$ is the modulus of elasticity.

\section{Mandibular graft design}

The models with high-quality volume meshes was exported as Abaqus file (.inp) for topological optimization. To compare the performance of the PLA printed grafts with original mandible, the bone material properties were also imported to Abaqus for FEA study. The reconstructed model was first split into two parts, shell and core, as shown in Fig. 3.

The shell was to maintain the original shape of the jawbone, and the thickness was set to $1.5 \mathrm{~mm}$. The core was designed by topological optimization in Abaqus to form porous scaffold structure. Topology optimization is a mathematical method, which can optimize material layout and maximize system performance under given conditions. The mathematical model of the topological optimization can be expressed as:

Find:

$$
a=\left(a_{1}, a_{2}, \cdots, a_{n}\right)^{T}
$$

Min:

$$
\begin{gathered}
C(a)=\frac{1}{2} F^{T} M \\
\text { S.t. }\left\{\begin{array}{c}
\frac{V^{*}}{V}=p \\
F=N M \\
0<a_{\min } \leq a_{i} \leq 1(i=1,2, \cdots, n)
\end{array}\right.
\end{gathered}
$$

where, $a_{i}$ is design variable whose value is continuous between $\left(a_{\text {min }}, 1\right)$ ( $a_{\text {min }}$ is a non-zero value to avoid singularity); $n$ is the number of optimum design variable; $C(a)$ is the global strain energy of the structure; $F$ is the global vector of structural force; $M$ is the global vector of structure displacement; $V$ and $V^{*}$ are the volume of structure before and after optimization; $p$ is the prescribed volume fraction; $N$ is the global stiffness matrix of the structure.

The design of mandibular graft is shown in Fig. 4.

This study provided other two designed grafts with porous scaffold structure for comparison [39-42]. The porous scaffold structure contained distinct mesh configurations and a highly interconnected macroporous network. The macroporous structures were aligned with same intervals without going through the topology optimization process. Figure 5 shows the graft with round-pore struts. The radius of the circle was $2.5 \mathrm{~mm}$, and the distance between adjacent circle centers was 6 $\mathrm{mm}$. Figure 6 shows the graft with square-pore struts. The square diagonal was $5 \mathrm{~mm}$, and the distance between adjacent square centers was $6 \mathrm{~mm}$.

\section{D printing and anisotropic constitutive model}

Grafts in this study were fabricated using an FDM 3D printer with a $210 \times 150 \times 100 \mathrm{~mm}$ build space (CEL Robox, UK). The grafts were fabricated layer-by-layer deposition of molten PLA material via FDM method. Each layer solidified at different intervals. The bonding between layers is relatively weaker than the material itself, causing the variation in the uniaxial tension strength with directions and anisotropic behavior. This study considered the effect of anisotropy of material on the mechanical behavior of graft, and proposed a constitutive model, which is expressed as follow:

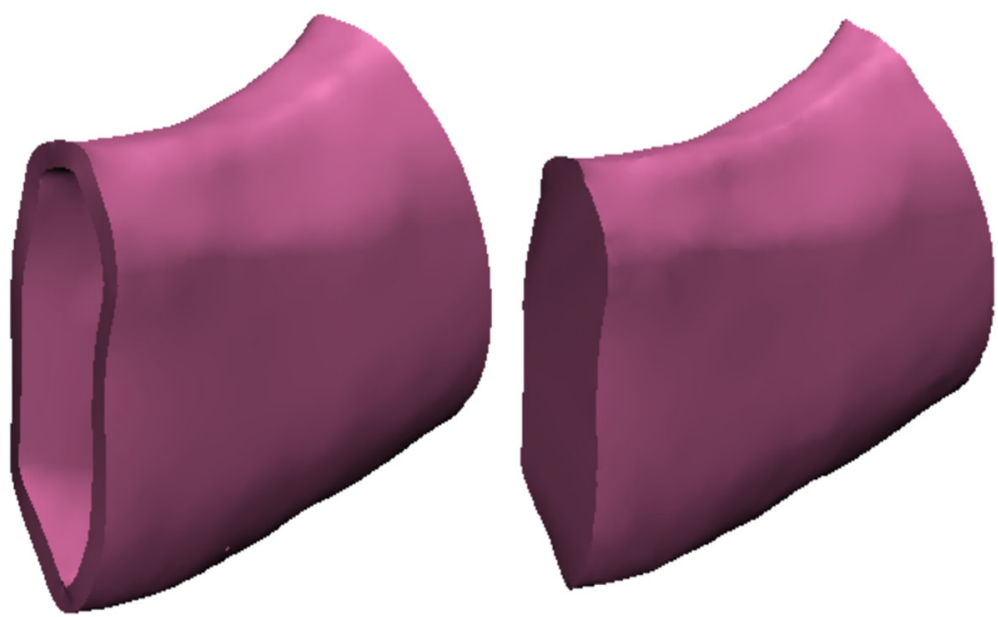

Fig. 3 Reconstructed mandible shell (left) and core (right) 


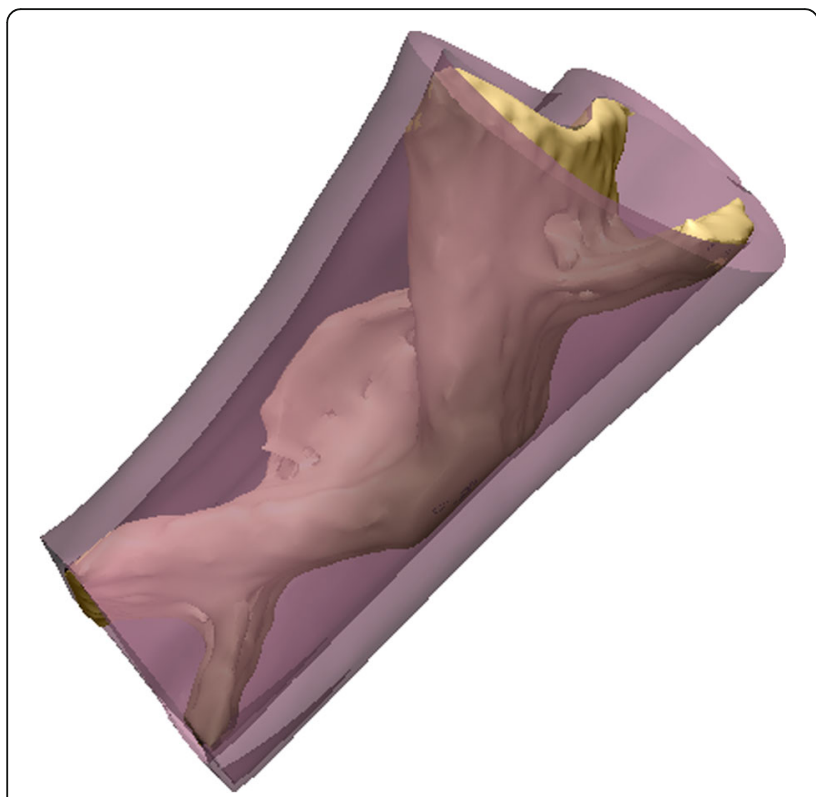

Fig. 4 Graft with topological optimized-pore scaffold structure

$$
\left[\begin{array}{c}
\varepsilon_{11} \\
\varepsilon_{22} \\
\varepsilon_{33} \\
\gamma_{12} \\
\gamma_{13} \\
\gamma_{23}
\end{array}\right]=\left[\begin{array}{cccccc}
\frac{1}{E_{1}} & -\frac{v_{21}}{E_{1}} & -\frac{v_{31}}{E_{3}} & 0 & 0 & 0 \\
-\frac{v_{12}}{E_{1}} & \frac{1}{E_{1}} & -\frac{v_{32}}{E_{3}} & 0 & 0 & 0 \\
-\frac{v_{13}}{E_{1}} & -\frac{v_{23}}{E_{1}} & \frac{1}{E_{3}} & 0 & 0 & 0 \\
0 & 0 & 0 & \frac{1}{G_{12}} & 0 & 0 \\
0 & 0 & 0 & 0 & \frac{1}{G_{13}} & 0 \\
0 & 0 & 0 & 0 & 0 & \frac{1}{G_{23}}
\end{array}\right]\left[\begin{array}{c}
\sigma_{11} \\
\sigma_{22} \\
\sigma_{33} \\
\tau_{12} \\
\tau_{13} \\
\tau_{23}
\end{array}\right]
$$

where, 1,2 and 3 are the principal axes directions; $\varepsilon$ is the normal strain; $\gamma$ is the shear strain; $\sigma$ is the normal stress; $\tau$ is the shear stress; $E$ is the Young's modulus; $v$ is the Poisson's ratio; $G$ is the shear modulus of the material.

The Young's and shear moduli of the two perpendicular directions, and the corresponding Poisson's ratios are the same. Thus, the material comes close to being a transversely isotropic material. Transverse isotropy is a special subclass of orthotropic and characterized by a plane of isotropy at every point in the material. Assuming 1-2 plane is the plane of isotropy at every point, transverse isotropy requires $E_{1}=E_{2}=E_{p}, v_{31}=v_{32}=v_{t p}, v_{13}=v_{23}=v_{p t}$, $G_{13}=G_{23}=G_{b}$ where $p$ and $t$ stand for "in-plane" and "transverse," respectively. Thus, $v_{t p}$ has the physical interpretation of the Poisson's ratio that characterizes the strain in the plane of isotropy resulting from stress normal to it. $v_{p t}$ characterizes the transverse strain in the direction normal to the plane of isotropy resulting from stress in the plane of isotropy. The stress-strain laws reduce to

$$
\left[\begin{array}{l}
\varepsilon_{11} \\
\varepsilon_{22} \\
\varepsilon_{33} \\
\gamma_{12} \\
\gamma_{13} \\
\gamma_{23}
\end{array}\right]=\left[\begin{array}{cccccc}
\frac{1}{E_{p}} & -\frac{v_{p}}{E_{p}} & -\frac{v_{t p}}{E_{t}} & 0 & 0 & 0 \\
-\frac{v_{p}}{E_{p}} & \frac{1}{E_{p}} & -\frac{v_{t p}}{E_{t}} & 0 & 0 & 0 \\
-\frac{v_{p t}}{E_{p}} & -\frac{v_{p t}}{E_{t}} & \frac{1}{E_{3}} & 0 & 0 & 0 \\
0 & 0 & 0 & \frac{1}{G_{p}} & 0 & 0 \\
0 & 0 & 0 & 0 & \frac{1}{G_{t}} & 0 \\
0 & 0 & 0 & 0 & 0 & \frac{1}{G_{t}}
\end{array}\right]\left[\begin{array}{c}
\sigma_{11} \\
\sigma_{22} \\
\sigma_{33} \\
\tau_{12} \\
\tau_{13} \\
\tau_{23}
\end{array}\right]
$$

where

$$
G_{p}=E_{p} / 2\left(1+v_{p}\right) .
$$

The total number of independent parameters was only five. These parameters were obtained by designing a three-point bending test of 3D printed beam specimens.
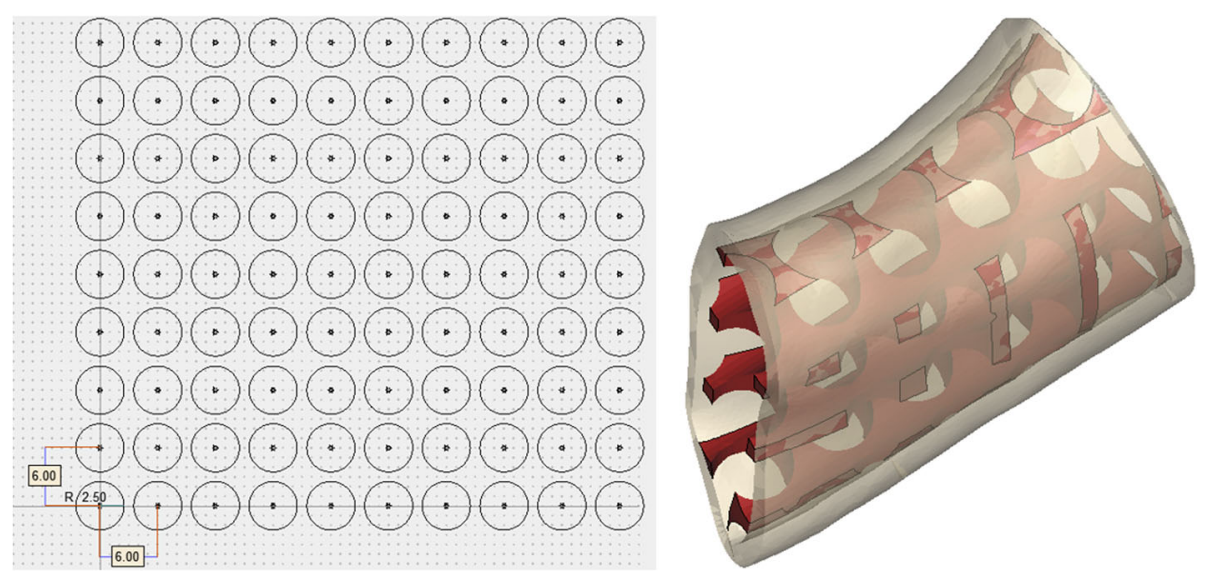

Fig. 5 Graft with the round-pore scaffold structure 

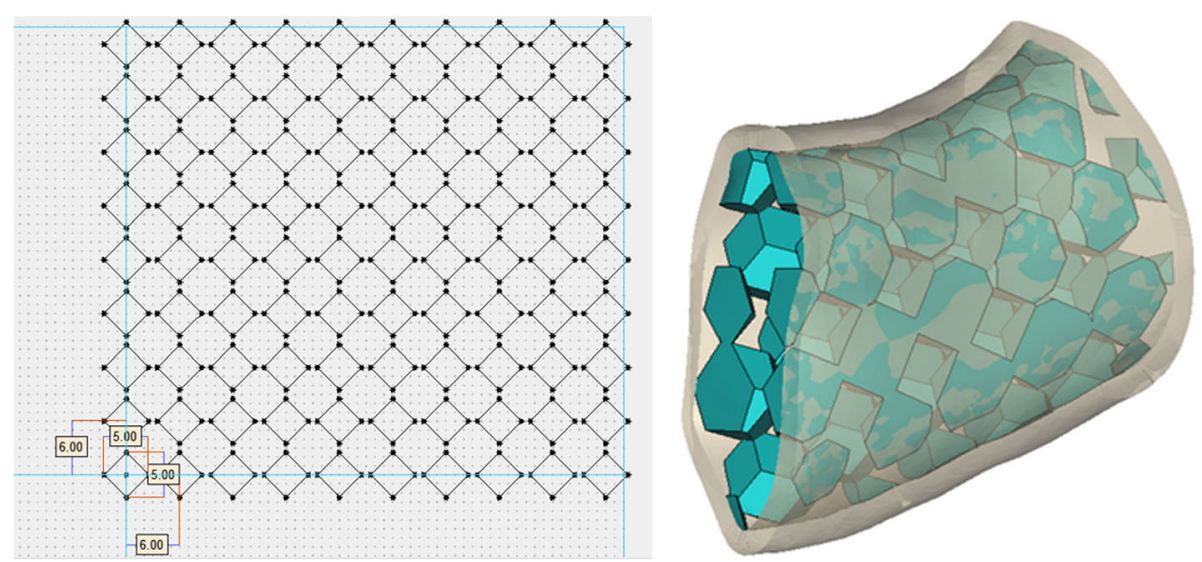

Fig. 6 Graft with the square-pore scaffold structure

To evaluate the effect of printing direction on mechanical behavior, all three designed graft models were imported into the 3D printer by STL file format and printed with 0,45 and 90 degrees orientations with PLA material. Figure 7 shows the graft models with different printing angle. The nozzle diameter was set as $0.4 \mathrm{~mm}$ while the layer thickness was set as $0.1 \mathrm{~mm}$. According to the printed specimens, the resolution of the printer was sufficient to print the designed microstructure of the graft. Some post-processing such as polish, cutting and support removing were also conducted.

\section{Three-point-bending test}

A three-point-bending jig was used to evaluate mechanical behaviors of the printed beams. The setup of the three-point bending test is shown in Fig. 8. The lower support spans were $20 \mathrm{~mm}$ apart and the upper loading nose was set an equal distance from each span. Two supporting rods and the loading nose had the same radius of $3.2 \mathrm{~mm} .0 .1 \mathrm{~mm} / \mathrm{min}$ was set for the loading velocity.

The beam specimens with different printing angle $0^{\circ}$, $45^{\circ}$ and $90^{\circ}$ were tested. The 0 -degree specimens had printing angle perpendicular to the loading cross-section; the 45 -degree specimens had a $45^{\circ}$ angle between loading cross-section and printing direction, and the 90-degree specimens had a printing angle parallel to the loading section. Three duplicate specimens were prepared for each printing angle with the same dimension. The dimensions were $30 \mathrm{~mm} \times 10 \mathrm{~mm} \times 5 \mathrm{~mm}$. The mid-span flexural stress and strain were calculated according to formulas provided by ASTM standard [43].

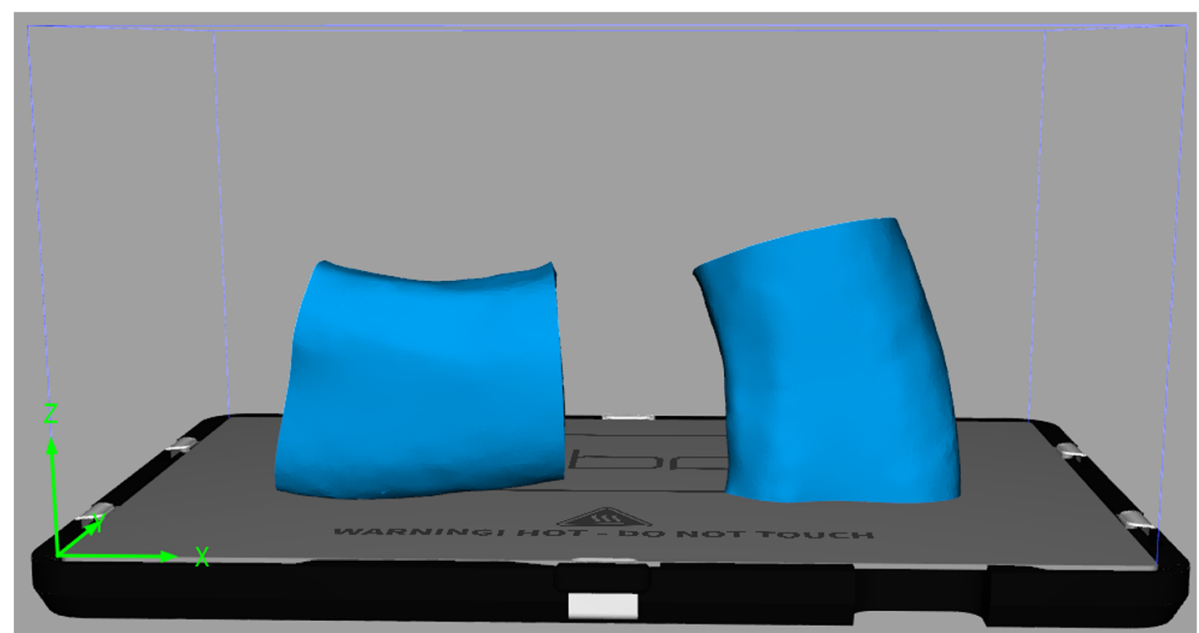

Fig. 7 Schematic of mandibular grafts with printing angle $0^{\circ}$ (left) and $90^{\circ}$ (right) 


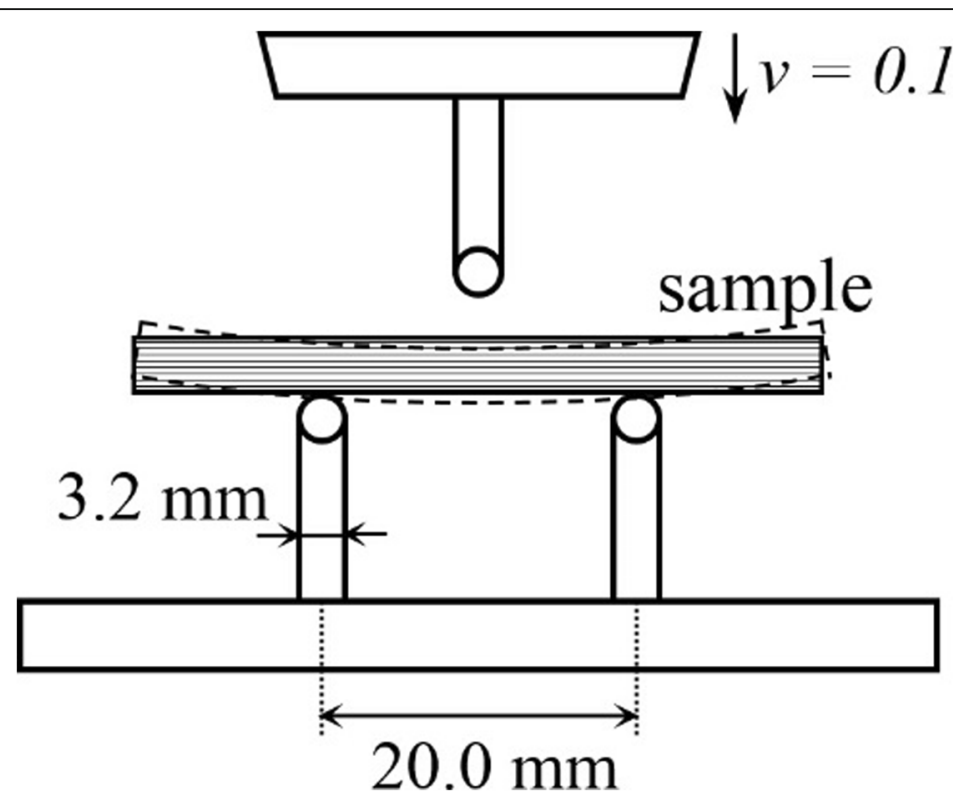

Fig. 8 Setup of three-point bending test

$$
\begin{gathered}
\sigma_{f}=\frac{3 P L}{2 b d^{2}} \\
\varepsilon_{f}=\frac{6 D d}{L^{2}}
\end{gathered}
$$

where, $\sigma_{f}$ is the flexural stress; $P$ is the load at the center of the beam; $L$ is the support span; $b$ is the width of beam tested; $d$ is the depth of beam tested; $\varepsilon_{f}$ is sample strain; $D$ is the deflection at the center of the beam.

In addition to the beam samples, the effect of printing angle $\left(0^{\circ}, 45^{\circ}\right.$ and $\left.90^{\circ}\right)$ of grafts on mechanical strength was also evaluated by a three-point bending test. Four grafts of each printing type were prepared and tested. Maximum load, field load, failure deflection and yield deflection were measured and the biomechanical behavior of each group was compared.

\section{Finite element analysis}

FEA calculations are based on finite element models that allow the validation of the experimental observations and calibrate the constitutive relationship between virtual and physical models [44]. The FE models were built with the material parameters obtained from the three-point bending test described in 2.5 using Abaqus. The transverse anisotropic material models were used with the principal axis set based on the printing directions. The digital grafts with different printing directions were subjected to loads corresponding to the three-point bending test. The initialization and propagation of cracks at the bottom were modeled with the extended finite element method (XFEM). The schematic setup of grafts subjected to loading is shown in
Fig. 9. The mechanical responses were obtained from the computational simulations.

\section{Results}

Three-point-bending test of beam specimens

Experimental data of the three-point bending test on beams were summarized in Fig. 10. The results show good repeatability of samples in the same group. The yield stress, failure stress, failure strain, ultimate strength and flexural modulus were calculated for each sample to better understand the mechanical performance of the printed material. The yield stress was calculated using the method of $0.2 \%$ offset; failure stress corresponds to the stress at failure strain, ultimate strength obtained from the maximum stress value. Flexural modulus was along the linear portion of the stress-strain curve. All these five properties were evaluated for each printed graft. The average value and standard deviation of each group are summarized in Table 1 . Figure 11 shows a typical failure mode and crack distribution of beam specimens from each group.

Based on the experimental results and computational model calibration, the following values of mechanical parameters were obtained for the anisotropic constitutive model (in the printing plane: $E_{1}=E_{2}=1590 \mathrm{MPa}, G_{12}=$ $722 \mathrm{MPa}$, perpendicular to the printing plane: $E_{3}=2050$ $\mathrm{MPa}, G_{23}=G_{13}=560 \mathrm{MPa}, v_{12}=v_{13}=v_{23}=0.42$.).

\section{The three-point bending test of grafts}

The results of three-point bending test from different types of printed grafts are summarized in Fig. 12. The "Round", "Square" and "Topology" indicate the grafts 


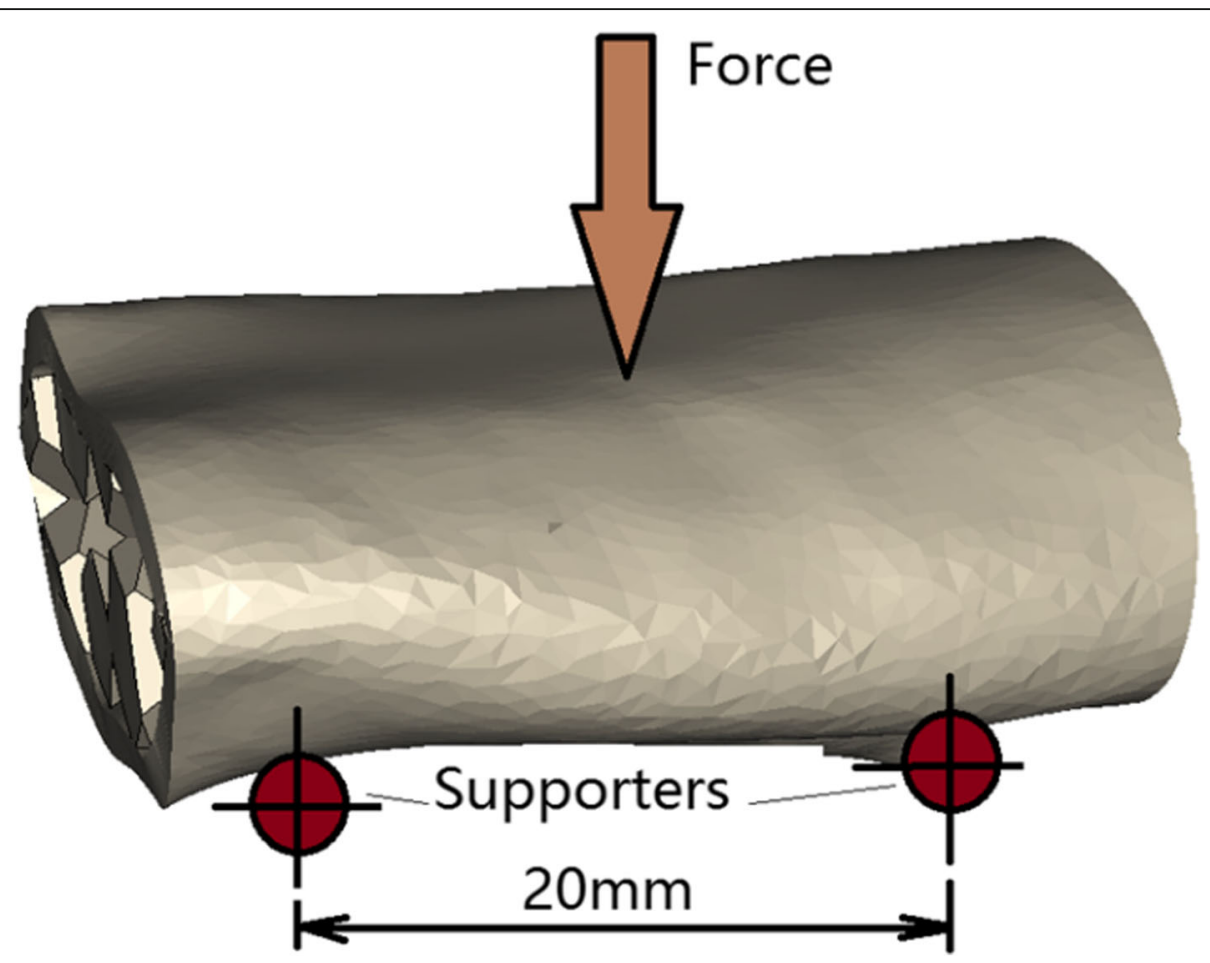

Fig. 9 Setup of grafts subjected to three-point bending load

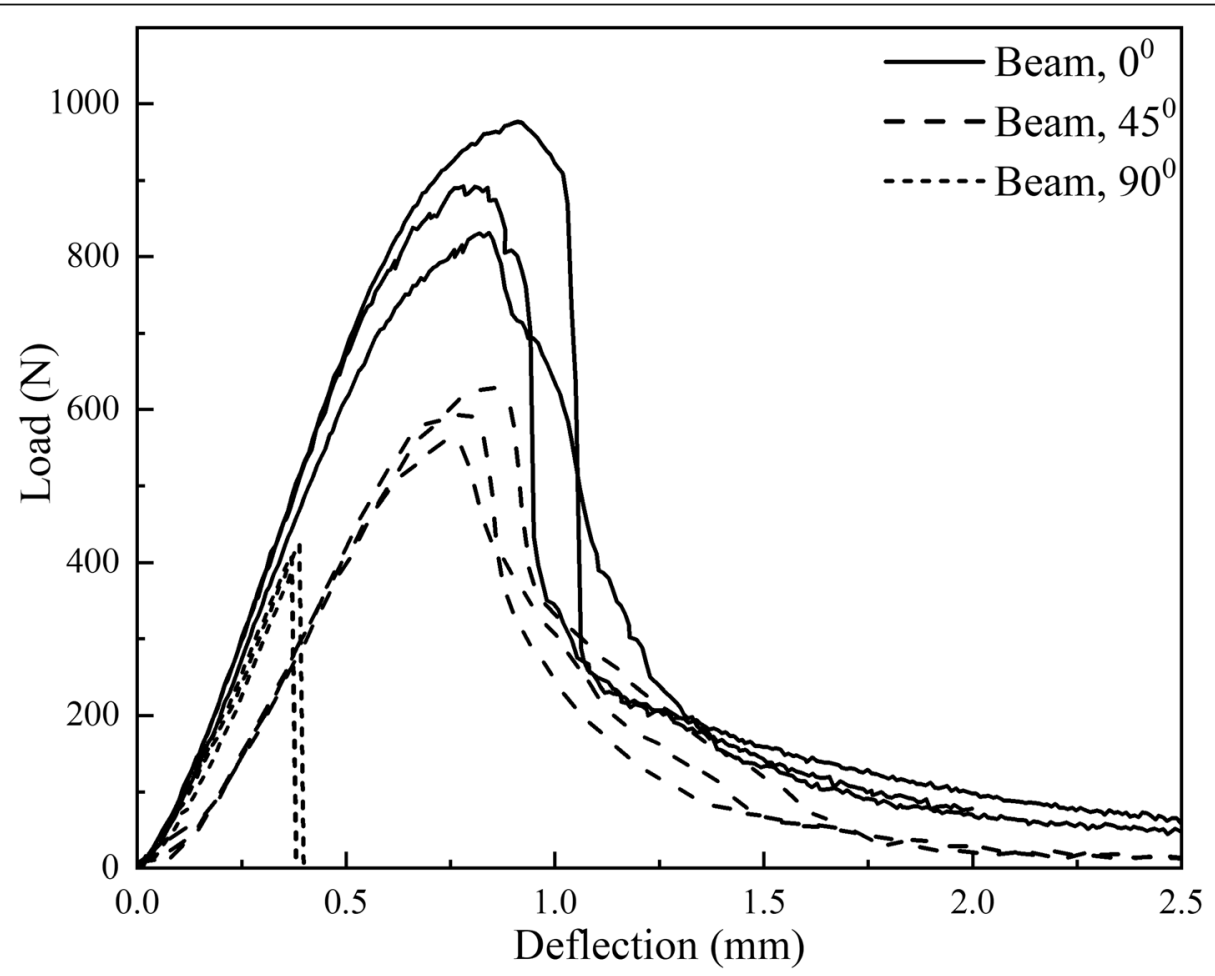

Fig. 10 Load-deflection curves of three-point bending test on beam specimens 
Table 1 Flexural properties of PLA beam specimens with three printing conditions

\begin{tabular}{llllll}
\hline Printing Angle (degree) & Ultimate Strength (MPa) & Yield Strength (MPa) & Failure Strength (MPa) & Failure Strain (\%) & Flexural Modulus (GPa) \\
\hline 0 & $107.98(7.13)^{\mathrm{a}}$ & $94.68(7.90)$ & $96.60(10.00)$ & $7.36(0.34)$ & $2.06(0.08)$ \\
45 & $71.53(3.45)$ & $69.70(3.73)$ & $68.26(2.80)$ & $5.77(0.47)$ & $1.21(0.03)$ \\
90 & $49.20(1.71)$ & $49.20(1.71)$ & $49.20(1.71)$ & $2.82(0.08)$ & $1.59(0.07)$ \\
\hline
\end{tabular}

${ }^{\mathrm{a} V a l u e s}$ in parentheses are the standard deviations of each group

with round-pore internal structure, square-pore structure, and topological optimized-pore internal structure, respectively. The effect of printing angle on mechanical behavior of maximum load, yield load, failure deflection and yield deflection were calculated and compared for each group, as shown in Fig. 13. Figure 14 shows the failure mode and crack propagation of different grafts printed with 0 and 90 degree angles. Three grafts on the left in Fig. 14 are the 0-degree printed samples while the three right samples were printed at 90-degree.

\section{The finite element analysis of grafts}

Figure 15 is the cross-sectional FEA results, which provide detailed information on maximum displacement, and Von Mises stress distribution of the three porous structures of grafts. For each graft, the left side displays the maximum displacement near the loading nose location and the global maximum displacement spot. The right side graph displays the Von Mises stress distribution. Since the anisotropic constitutive model proposed in this study is based on the linear-perfect plastic model

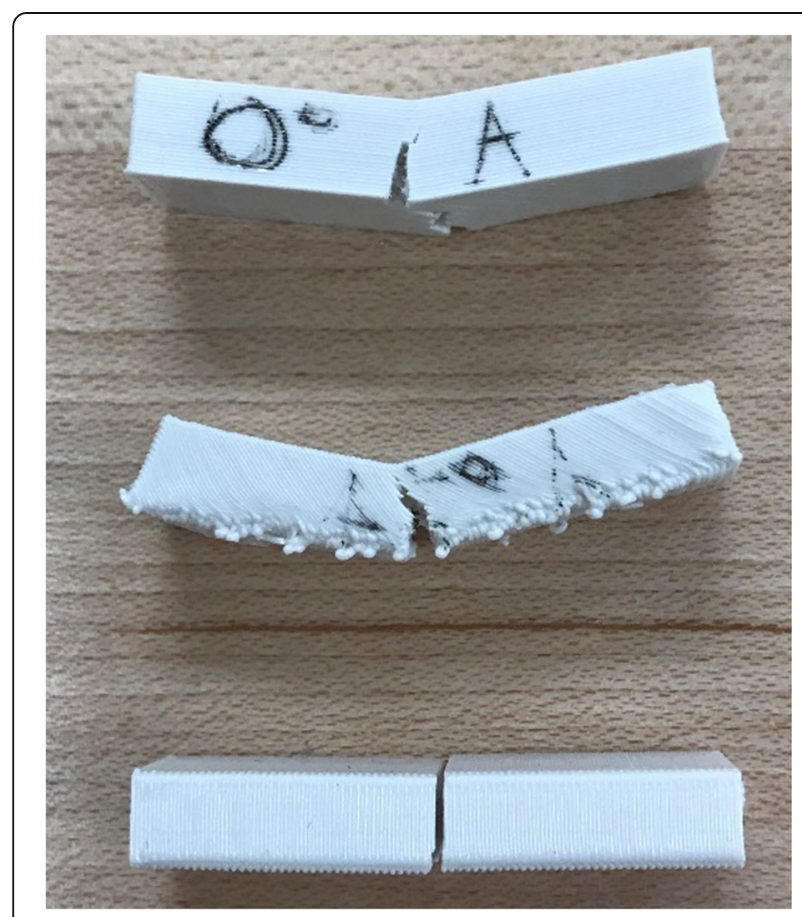

Fig. 11 Failure mode of three beam specimens with printing angle $0^{\circ}, 45^{\circ}, 90^{\circ}$ (from top to bottom) which is insufficient to capture the plastic stage and large deformation, all computational models were subjected to a $500 \mathrm{~N}$ three-point bending load that represents maximum chewing force from patients.

Table 2 lists the maximum principal strain, maximum Von Mises stress, maximum displacement and porosity of each design of graft. Porosity is a measure of the void spaces in a graft and is a fraction of the volume of voids over the total volume based on the reconstructed mandibular core scaffold. Porosity can be theoretically calculated from the 3D computational model and real porosity can be calculated from printed graft using Archimedes principle that the volume of displaced water is equal to the volume of the submerged object. When printing some models with spatial structure, like graft in this case, the printer will generate some supports to avoid structural collapse, and some supports are difficult to remove after printing. Therefore, the printed porosity is often slight smaller than designed porosity. However, the error in this study is below $5 \%$, which is acceptable.

\section{Discussion}

PLA has not been currently used as bone analogs for mandibular reconstruction surgery in load-bearing areas. Its excellent biocompatibility and biodegradation properties are important reason for extensively studied in the literature as a scaffolding material for tissue engineering in craniofacial areas. Further strategies to improve its mechanical properties based on PLA modifications and PLA nanocomposite designs may be the key to improve its mechanical properties for mandibular reconstruction. This project is to provide valid information for readers to understand mechanical issues of 3D printed biomaterials.

\section{Comparison of 3D printed beams with different printing angles}

The load-deflection curves of Fig. 10 from three-point bending test validate that the direction of printing angle has a substantial effect on the mechanical properties of $3 \mathrm{D}$ printed parts. From the load-deflection curves of beam printed at 0 -degree angle, the beam showed its elastic property in the initial loading stage. With the load increased, the beam entered the plastic stage, and plastic strain developed and cracked until global damage. The similar trend was observed from the load-deflection curves of beam printed at 45-degree angle. However, the 

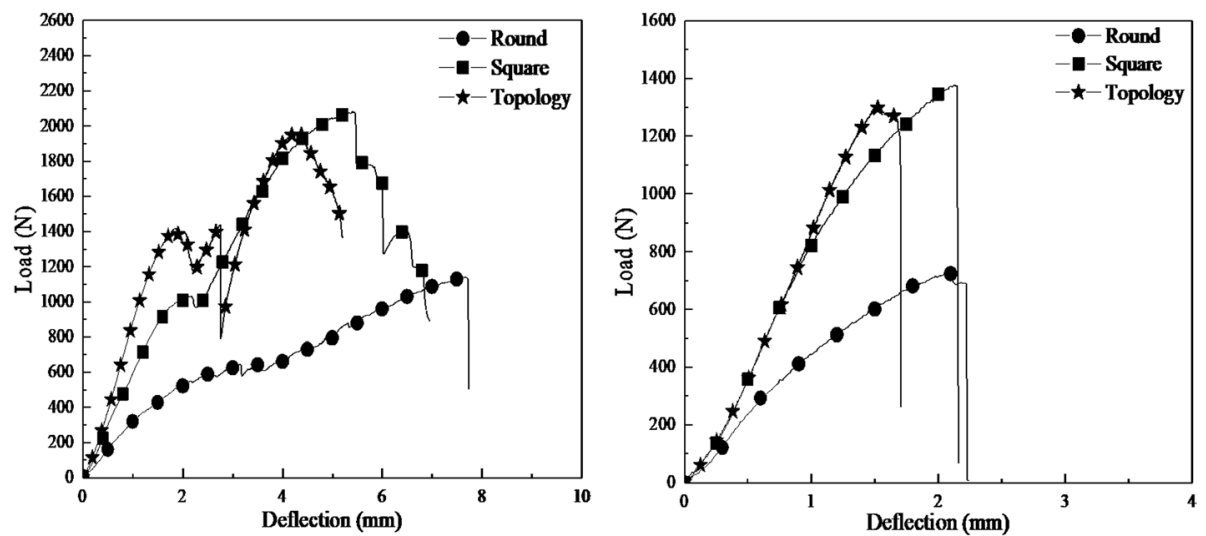

Fig. 12 Load-deflection curves of three-point bending test on grafts printed at 0-degree (left) and 90-degree (right)
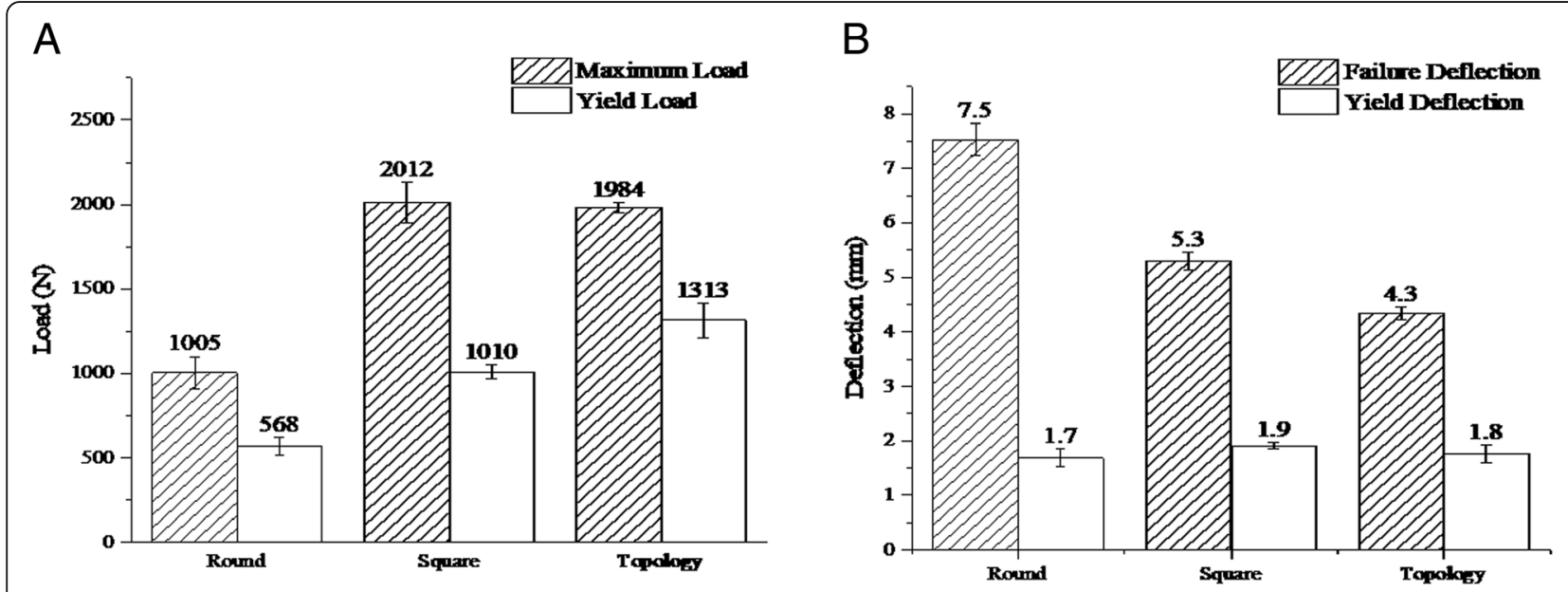

C

D
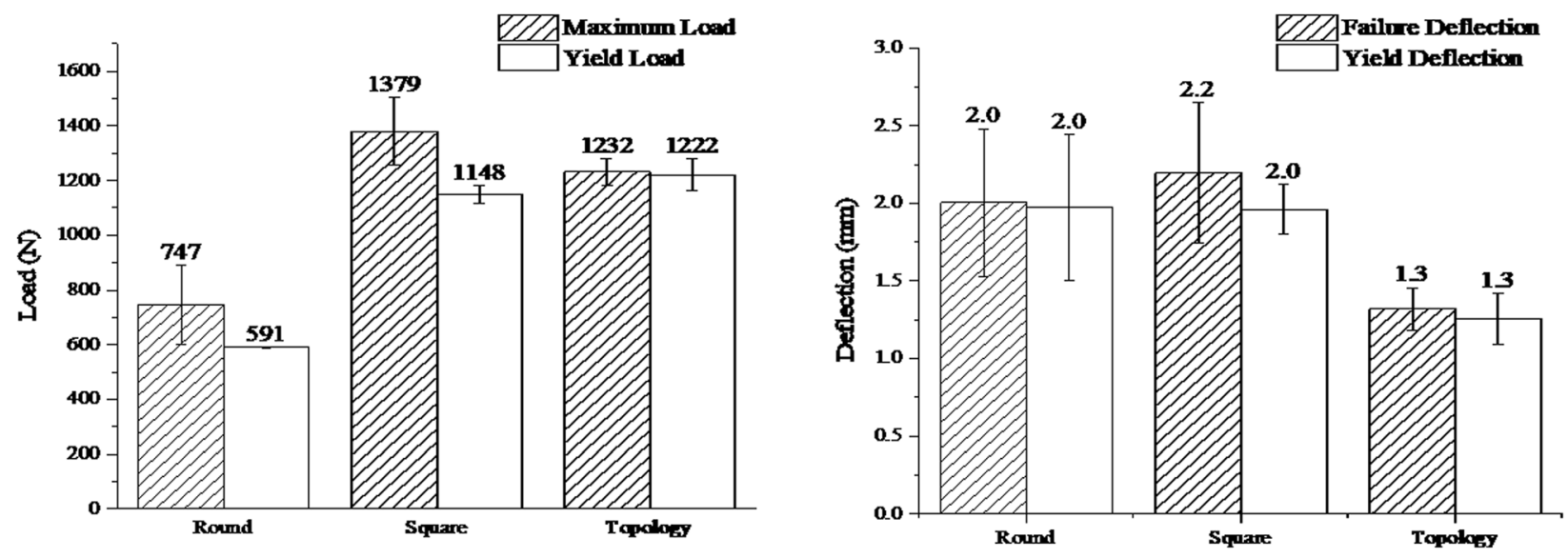

Fig. 13 Histograms of flexural properties for PLA grafts. a. Load of specimens printed at 0-degree. b. Deflection of specimens printed at 0-degree. c. Load of specimens printed at 90-degree. d. Deflection of specimens printed at 90-degree 


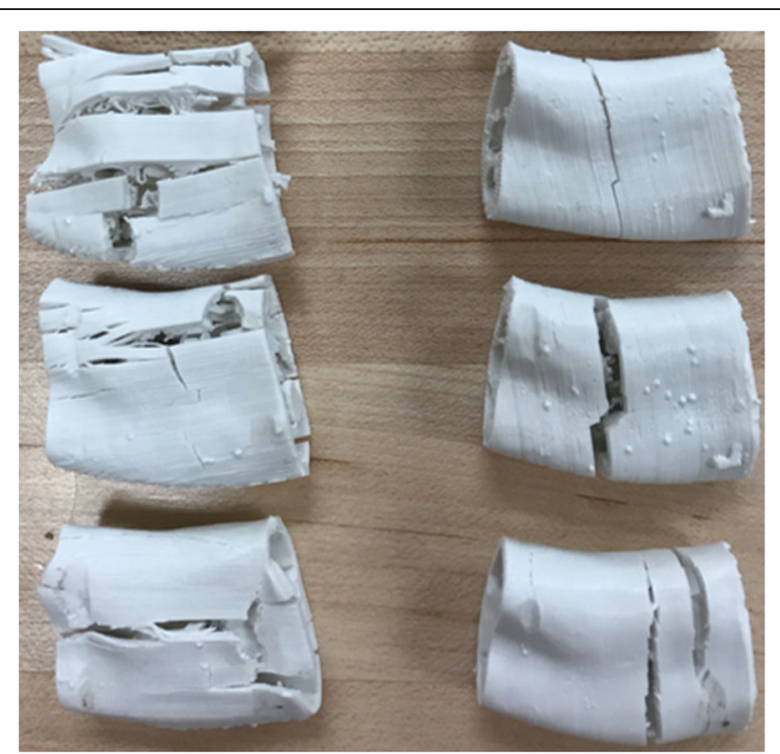

Fig. 14 Comparison of failed grafts with round-pore, square-pore and topological optimized-pore scaffold structures, from top to bottom printed at 0-degree (left) and 90-degree (right)

load-deflection curve for beam specimen printed at 90-degree angle doesn't show apparent yield or horizontal segment. After reaching the peak point, the crack propagates suddenly penetrated through the whole cross-section and the beam fractured into two parts. This is different from the flexural curves for the specimens printed at 0 -degree or 45-degree angles, which show slight plastic failure before their rupture occurred.

Figure 11 shows the beam specimens with 0 -degree printing angle presents flexural failure and the main cracks appeared in the mid-span and prorogated along the middle axis. The same failure mode can be seen in the beam specimens printed at 45-degree angle with cracks grew along 45-degree printing direction. For the beam specimens printed at 90-degree angle, it presents shear failure with the shear force exceeded the bond strength between the layers. The local failure and global failure occurred at a similar load. The beam was sheared off in the middle of the beam where the highest stress was concentrated.

The data from the three-point bending test of PLA (Table 1) also illustrate that all of the properties exhibit anisotropic behavior with property differences up to $60 \%$. The average ultimate strength of a specimen printed at 0 -degree was $54 \%$ higher than that of a specimen printed at 90 -degree and 34\% higher than that of those specimens printed at 45-degree. Similar patterns occurred on the failure stress and yield strength among those three groups. Furthermore, the average strain at failure was almost 2.5 times for the specimen printed at 0 -degree than that printed at 90-degree and was also
$14 \%$ higher than that printed at 45 -degree. There was a great effect of printing direction on flexural modulus shown in Table 1 . Flexural modulus values of specimens printed at 0 -degree were $23 \%$ higher than that printed at 90-degree and $41 \%$ higher than specimens printed at 45-degree. Overall, beam specimens printed at 0-degree clearly performed the best among the three groups.

\section{Comparison of 3D printed grafts with different printing angles}

The load-deflection curves from three-point bending test (Fig. 12) illustrate anisotropic behavior of printed grafts. Similar mechanical behavior trends are observed, i.e., elastic and plastic deformation, of grafts based on printing directions. The data of flexural properties for grafts (Fig. 13) show that the maximum load of each graft printed at 0 -degree is much higher than that of 90 -degree printed with differences up to $72 \%$. The average failure deflection of grafts printed at 0-degree was much higher than that of 90-degree printed with differences up to $73 \%$. The yield load and deflection are not significantly affected by printing angle. By combining the experimental data and failure mode of grafts, it is found that for grafts printed at 0-degree, local failure started from upper filament layers, the propagation of cracks was perpendicular to the direction of loading. As the deflection increased, the tensile force between the bottom filament layers exceeded the bond strength; the crack opening began to grow along the printing direction until the global failure occurred. On the contrast, for grafts printed at 90-degree, local failure began from the upper filament and then propagated along the loading direction, the global failure occurred at almost the same time since the bonding between the adjacent filaments was weak, and the cracks could easily penetrate through the whole filament layers. It explains why the direction of main crack propagation in Fig. 14 are different from grafts printed with $0^{\circ}$ and $90^{\circ}$. Also, it matches with the obtained results that the maximum load and deflection for grafts printed with $0^{0}$ are much higher than that of grafts printed with $90^{\circ}$.

\section{Comparison of the topological optimized graft with other designed grafts}

The results of the finite element analysis of mechanical behaviors of the printed grafts are presented in Table 2 . The maximum principal strain (\%), Von Mises stress $(\mathrm{MPa})$, and displacement $(\mathrm{mm})$ of the topological optimized grafts decreases $73 \%, 65 \%$, and $74 \%$ respectively when compared to those with round-pore structure design. Comparing to the square-pore structure, the optimized structure has a decrease of $51 \%$ in maximum principal strain, $31 \%$ in maximum stress, and $55 \%$ in displacement. The maximum Von Mises stress distribution 


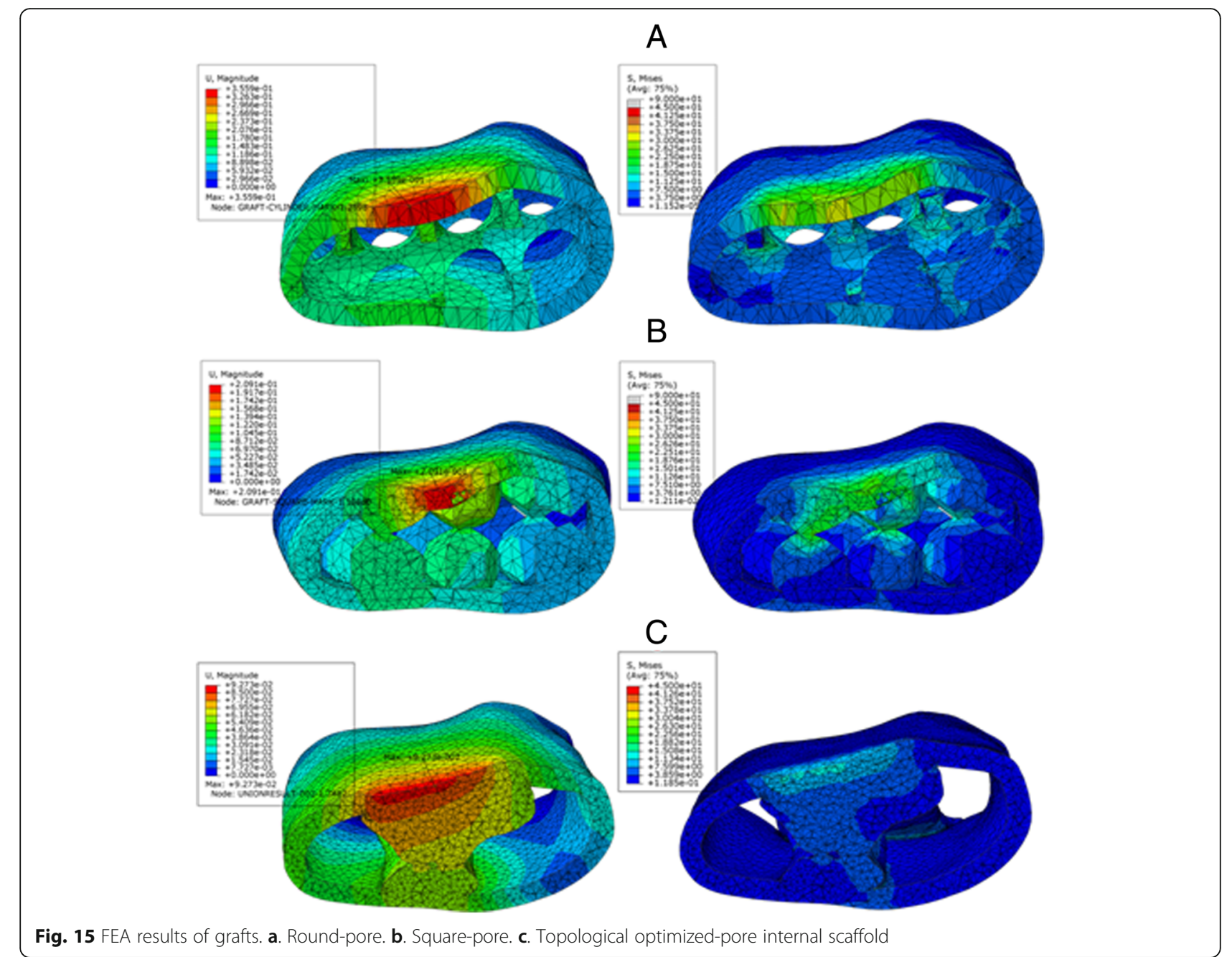

of grafts (Fig. 15) indicates that the stresses are always concentrated at the top aspect of the graft. The same pattern is observed with maximum displacement. The topological optimized graft has significantly better results as most of the meshes keep very small stress and the maximum stress is well below the allowable stress $(\sigma=90 \mathrm{MPa})$. In order to compare the mechanical behavior of designed grafts with human natural mandible, the model of original structure of the mandible was built with the material parameters obtained from the CBCT files described in 2.2 under using Abaqus. The maximum principal strain, maximum Von Mises stress, and maximum displacement of original mandible model are $0.232 \%, 15.427 \mathrm{MPa}$, and $0.090 \mathrm{~mm}$ respectively. The topological optimized graft has the mechanical properties close to the real bone in terms of the maximum Von Mises stress and maximum displacement. The maximum principal strain of the optimized graft is slightly higher than that of the human mandible, which may be led by the difference of Young's modulus and density between the bone and PLA material. The average Young's modulus and density of bone in this patient are 10GPa and $1500 \mathrm{~kg} / \mathrm{m}^{3}$, which is much higher than that of the PLA materials with $2 \mathrm{GPa}$ and $1200 \mathrm{~kg} / \mathrm{m}^{3}$. However, the

Table 2 Flexural properties for the PLA grafts

\begin{tabular}{llllll}
\hline Porous Structure & Max Principal Strain (\%) & Max Von Mises Stress (MPa) & Max Displacement $(\mathrm{mm})$ & Theoretical Porosity (\%) & Real Porosity (\%) \\
\hline Round & 1.972 & 49.386 & 0.356 & 77 & $75(3)$ \\
Square & 1.077 & 25.045 & 0.208 & 58 & $55(2)$ \\
Topology & 0.533 & 17.331 & 0.093 & 67 & $65(2)$ \\
\hline
\end{tabular}

${ }^{a}$ Values in parentheses are the standard deviations of each group 
mechanical properties of the other two designed grafts are relatively poor, which cannot provide a good environment for defect repair in clinic.

The real porosity (\%) of the topological optimized graft is 65 , which increases $15 \%$ when compared to the grafts with square-pore structure. Although the porosity of topological optimized graft is lower than graft with round-pore scaffold structure, the strength and stiffness are significantly improved. The results verify that the topological optimization method is capable of optimizing the grafts by assigning more strut elements to the stress concentration area and removing strut elements from the low-stress area. In this way, graft can have higher space utilization, higher strength and stability, and more uniform stress distribution. However, these two conventional grafts use uniform configuration of strut elements, which can cause stress concentration and material waste. Overall, the printed graft designed by topological optimization method provides high strength, stiffness, and porosity that can provide a conducive environment from mechanical and biological perspectives.

\section{Conclusions}

A new method of restoring segmental bony defects of the mandible to its exact original shape, size and form is proposed by using 3D printing technology and topological optimization method. 3D printing technology can easily fabricate complex shapes to match patients' unique defects. The 3D printed graft samples had anisotropic properties. Printing direction and internal design of the grafts significantly affected their mechanical properties. The grafts printed at $0^{\circ}$ with topology optimization had the best results. Although the results of this study are based on PLA material, the proposed methodologies are also applicable to other promising $3 \mathrm{D}$ printing materials such as Polyetheretherketone (PEEK). 3D printing technology and topological optimization are useful tools in fabrication and designing bone analogs for mandibular reconstruction.

\section{Abbreviations \\ ABS: Acrylonitrile butadiene styrene; CBCT: Cone beam computed tomography; FDM: Fused deposition modeling; FEM: Finite element modeling; PLA: Polylactic Acid}

\section{Acknowledgements}

The James Hayward Research Fund funds the article processing charge for this publication.

\section{Funding}

The project is partially supported by the James Hayward Research Fund.

\section{Availability of data and materials}

Readers interested in data should contact the authors.

\section{Authors' contributions}

$\mathrm{JH}$ conducted experiments, collected data and drat the manuscript; JHW conceived the study, interpret the data and revised the manuscript; RW: designed the study and interpreted the data; $Y L, X Y$, and DAB: edited the manuscript. All authors read and approved the final manuscript.
Ethics approval and consent to participate

Not applicable.

\section{Consent for publication}

Informed consent was obtained from all individual participants included in the study.

\section{Competing interests}

The authors declare that they have no competing interests.

\section{Publisher's note}

Springer Nature remains neutral with regard to jurisdictional claims in published maps and institutional affiliations.

\section{Author details}

'Department of Electrical Engineering and Computer Science, Case Western Reserve University School of Engineering, Cleveland, OH 44106-7201, USA.

${ }^{2}$ Department of Orthopedic Surgery, Case Medical Center, Cleveland, OH 44106, USA. ${ }^{3}$ Department of Comprehensive Care, Case Western Reserve University School of Dental Medicine, Cleveland, OH, USA. ${ }^{4}$ Department of Civil Engineering, Case Western Reserve University School of Engineering, Cleveland, OH 44106-7201, USA. ${ }^{5}$ Key Laboratory of E\&M (Zhejiang University of Technology), Ministry of Education \& Zhejiang Province, Hangzhou 310014, Zhejiang Province, China. ${ }^{6}$ Department of Maxillofacial Surgery, Case Western Reserve University School of Dental Medicine, Cleveland, OH 44106, USA.

Received: 24 August 2018 Accepted: 19 February 2019

Published online: 14 March 2019

\section{References}

1. Dendrinos $G$, Kontos $S$, Lyritsis $E$. Use of the llizarov technique for treatment of non-union of the tibia associated with infection. JBJS. 1995;77(6):835-46.

2. Chadayammuri V, Hake M, Mauffey C. Innovative strategies for the management of long bone infection: a review of the Masquelet technique. Patient safety in surgery. 2015;9(1):32.

3. Zorn K. Segmental tibial defects. Comparing conventional and llizarov methodologies. Clinical orthopaedics and related research. 1994;301:118-23.

4. Eshraghi S, Das S. Mechanical and microstructural properties of polycaprolactone scaffolds with one-dimensional, two-dimensional, and three-dimensional orthogonally oriented porous architectures produced by selective laser sintering. Acta Biomater. 2010;6(7):2467-76. https://doi.org/10. 1016/j.actbio.2010.02.002.

5. Marcos-Campos I, et al. Bone scaffold architecture modulates the development of mineralized bone matrix by human embryonic stem cells. Biomaterials. 2012:33(33):8329-42. https://doi.org/10.1016/j.biomaterials.2012.08.013.

6. Syahrom A, et al. Permeability studies of artificial and natural cancellous bone structures. Med Eng Phys. 2013;35(6):792-9. https://doi.org/10.1016/j. medengphy.2012.08.011.

7. Rajagopalan S, Robb RA. Schwarz meets Schwann: design and fabrication of biomorphic and durataxic tissue engineering scaffolds. Med Image Anal. 2006;10(5):693-712. https://doi.org/10.1016/.media.2006.06.001.

8. Voronov $R$, et al. Computational modeling of flow-induced shear stresses within 3D salt-leached porous scaffolds imaged via micro-CT. J Biomech. 2010;43(7):1279-86. https://doi.org/10.1016/j.jbiomech.2010.01.007.

9. Chana JS, et al. Segmental mandibulectomy and immediate free fibula osteoseptocutaneous flap reconstruction with endosteal implants: an ideal treatment method for mandibular ameloblastoma. Plast Reconstr Surg. 2004;113(1):80-7. https://doi.org/10.1097/01.PRS.0000097719.69616.29.

10. Gbara A, et al. Long-term results of jaw reconstruction with microsurgical fibula grafts and dental implants. J Oral Maxillofac Surg. 2007;65(5):1005-9. https://doi.org/10.1016/j.joms.2006.06.294.

11. Wang $R$, et al. Effect of interfragmentary gap on the mechanical behavior of mandibular angle fracture with three fixation designs: a finite element analysis. J Plast Reconstr Aesthet Surg. 2017;70(3):360-9. https://doi.org/10. 1016/j.bjps.2016.10.026.

12. Ferri J, et al. Advantages and limitations of the fibula free flap in mandibular reconstruction. J Oral Maxillofac Surg. 1997;55(5):440-8. https://doi.org/10. 1016/50278-2391(97)90685-6.

13. Modabber A, et al. Evaluation of computer-assisted jaw reconstruction with free vascularized fibular flap compared to conventional surgery: a clinical 
pilot study. The International Journal of Medical Robotics and Computer Assisted Surgery. 2012;8(2):215-20. https://doi.org/10.1002/rcs.456.

14. Montazerian $\mathrm{H}$, et al. Porous scaffold internal architecture design based on minimal surfaces: a compromise between permeability and elastic properties. Mater Des. 2017;126:98-114. https://doi.org/10.1016/j.matdes. 2017.04.009.

15. Pobloth A-M, et al. Mechanobiologically optimized 3D titanium-mesh scaffolds enhance bone regeneration in critical segmental defects in sheep. Science translational medicine. 2018;10(423):eaam8828. https://doi.org/10.1126/ scitranslmed.aam8828.

16. Ahn S-H, et al. Anisotropic material properties of fused deposition modeling ABS. Rapid Prototyp J. 2002;8(4):248-57. https://doi.org/10.1108/ 13552540210441166.

17. Masood S, Song W. Development of new metal/polymer materials for rapid tooling using fused deposition modelling. Mater Des. 2004;25(7):587-94. https://doi.org/10.1016/..matdes.2004.02.009.

18. Lee Y-B, et al. Bio-printing of collagen and VEGF-releasing fibrin gel scaffolds for neural stem cell culture. Exp Neurol. 2010;223(2):645-52. https://doi.org/ 10.1016/j.expneurol.2010.02.014

19. Murphy SV, Skardal A, Atala A. Evaluation of hydrogels for bio-printing applications. J Biomed Mater Res A. 2013;101(1):272-84. https://doi.org/10. 1002/jbm.a.34326

20. Schieker $\mathrm{M}$, et al. Biomaterials as scaffold for bone tissue engineering European journal of trauma. 2006;32(2):114-24. https://doi.org/10.1007/ s00068-006-6047-8.

21. Yang $\mathrm{S}$, et al. The design of scaffolds for use in tissue engineering. Part I. Traditional factors. Tissue Eng. 2001;7(6):679-89. https://doi.org/10.1089/ 107632701753337645.

22. Habibovic $\mathrm{P}$, et al. Osteoconduction and osteoinduction of low-temperature 3D printed bioceramic implants. Biomaterials. 2008;29(7):944-53. https://doi. org/10.1016/j.biomaterials.2007.10.023.

23. Es-Said O, et al. Effect of layer orientation on mechanical properties of rapid prototyped samples. Mater Manuf Process. 2000;15(1):107-22. https://doi. org/10.1080/10426910008912976

24. Bellini A, Güçeri S. Mechanical characterization of parts fabricated using fused deposition modeling. Rapid Prototyp J. 2003;9(4):252-64. https://doi. org/10.1108/13552540310489631.

25. Hill N, Haghi M. Deposition direction-dependent failure criteria for fused deposition modeling polycarbonate. Rapid Prototyp J. 2014;20(3):221-7. https://doi.org/10.1108/RPJ-04-2013-0039.

26. Lee $C$, et al. Measurement of anisotropic compressive strength of rapid prototyping parts. J Mater Process Technol. 2007;187:627-30.

27. Shum HC, Kim J-W, Weitz DA. Microfluidic fabrication of monodisperse biocompatible and biodegradable polymersomes with controlled permeability. J Am Chem Soc. 2008;130(29):9543-9. https://doi.org/10.1021/ ja802157y.

28. Rosenzweig DH, et al. 3D-printed ABS and PLA scaffolds for cartilage and nucleus pulposus tissue regeneration. Int J Mol Sci. 2015;16(7):15118-35. https://doi.org/10.3390/ijms160715118.

29. Anderson JM, Shive MS. Biodegradation and biocompatibility of PLA and PLGA microspheres. Adv Drug Deliv Rev. 1997;28(1):5-24. https://doi.org/10. 1016/S0169-409X(97)00048-3.

30. Hollister SJ, Maddox R, Taboas JM. Optimal design and fabrication of scaffolds to mimic tissue properties and satisfy biological constraints. Biomaterials. 2002;23(20):4095-103. https://doi.org/10.1016/S01429612(02)00148-5.

31. Kang $\mathrm{H}$, Lin C-Y, Hollister SJ. Topology optimization of three dimensional tissue engineering scaffold architectures for prescribed bulk modulus and diffusivity. Struct Multidiscip Optim. 2010;42(4):633-44. https://doi.org/10. 1007/s00158-010-0508-8.

32. Lin CY, Kikuchi N, Hollister SJ. A novel method for biomaterial scaffold internal architecture design to match bone elastic properties with desired porosity. J Biomech. 2004;37(5):623-36. https://doi.org/10.1016/j.jbiomech. 2003.09.029

33. Liu Y-F, et al. A customized fixation plate with novel structure designed by topological optimization for mandibular angle fracture based on finite element analysis. Biomedical engineering online. 2017;16(1):131.

34. Cohen A, et al. Mandibular reconstruction using stereolithographic 3dimensional printing modeling technology. Oral Surgery, Oral Medicine, Oral Pathology, Oral Radiology, and Endodontology. 2009;108(5):661-6. https://doi.org/10.1016/j.tripleo.2009.05.023.
35. Ludlow JB, et al. Dosimetry of $3 \mathrm{CBCT}$ devices for oral and maxillofacial radiology: CB Mercuray, NewTom 3G and i-CAT. Dentomaxillofacial Radiology. 2006;35(4):219-26. https://doi.org/10.1259/dmfr/14340323.

36. Ludlow JB, Ivanovic M. Comparative dosimetry of dental CBCT devices and 64-slice CT for oral and maxillofacial radiology. Oral Surgery, Oral Medicine, Oral Pathology, Oral Radiology, and Endodontology. 2008;106(1):106-14. https://doi.org/10.1016/j.tripleo.2008.03.018.

37. Abdullah JY, et al. Comparison of 3D reconstruction of mandible for preoperative planning using commercial and open-source software. In AIP Conference Proceedings. 2016. AIP Publishing.

38. Liu Y-F, et al. Digital design and fabrication of simulation model for measuring orthodontic force. Biomed Mater Eng. 2014;24(6):2265-71. https://doi.org/10.3233/BME-141039.

39. Drury $\mathrm{L}$, Mooney DJ. Hydrogels for tissue engineering: scaffold design variables and applications. Biomaterials. 2003;24(24):4337-51. https://doi.org/ 10.1016/S0142-9612(03)00340-5.

40. Hollister SJ. Porous scaffold design for tissue engineering. Nat Mater. 2005; 4(7):518. https://doi.org/10.1038/nmat1421.

41. Hutmacher, D.W, Scaffolds in tissue engineering bone and cartilage, in The Biomaterials: Silver Jubilee Compendium. 2006, Elsevier. p. 175-189, DOl: https://doi.org/10.1158/2326-6066.CIR-18-0566.

42. Yoshimoto $\mathrm{H}$, et al. A biodegradable nanofiber scaffold by electrospinning and its potential for bone tissue engineering. Biomaterials. 2003;24(12): 2077-82. https://doi.org/10.1016/S0142-9612(02)00635-X.

43. Astm I. Standard test methods for flexural properties of unreinforced and reinforced plastics and electrical insulating materials. ASTM. 2007:D790-07.

44. Viceconti $M$, et al. Extracting clinically relevant data from finite element simulations. Clin Biomech. 2005;20(5):451-4. https://doi.org/10.1016/j. clinbiomech.2005.01.010.

\section{Ready to submit your research? Choose BMC and benefit from:}

- fast, convenient online submission

- thorough peer review by experienced researchers in your field

- rapid publication on acceptance

- support for research data, including large and complex data types

- gold Open Access which fosters wider collaboration and increased citations

- maximum visibility for your research: over $100 \mathrm{M}$ website views per year

At BMC, research is always in progress.

Learn more biomedcentral.com/submissions 